Journal of Advanced College of Engineering and Management, Vol. 4, 2018

\title{
PROSPECTIVE OF CURRICULUM REVISION IN MECHANICAL ENGINEERING, INSTITUTE OF ENGINEERING TRIBHUVAN UNIVERSITY
}

\author{
Rajendra Shrestha \\ Department of Mechanical Engineering, Pulchowk Campus, Institute of Engineering, \\ Tribhuvan University, Lalitpur, Nepal \\ Email Address:rsfluid@hotmail.com
}

\begin{abstract}
Continuous revision of curriculum is important in academic institutions. First revision of the curriculum of Mechanical Engineering was completed in 1999. Second revision of the curriculum was started in 2009 and completed in 2015. It is important for engineering practice to make competitive curriculum for producing quality students by using modern techniques, skills and engineering tools.

Analysis of Curriculum-1999 and 2009 were performed. General out lines of the curriculum revisions were introduced. Features of the curriculum revisions were discussed in detail. Competitive analysis of curriculums of contemporise universities of Asia were performed. Accreditation process were analysed, taking reference of European and American systems. Updating equipment in workshop and laboratories with latest technologies were found necessary.
\end{abstract}

Key words: Curriculum (C), Institute of Engineering (IOE), credit, courses contact hours

\section{Introduction}

Department of Mechanical Engineering is one of the six engineering departments of the Pulchowk Campus, Institute of Engineering, Tribhuvan University, Nepal. It has started the bachelors program in the year 1995. This program is offered in Thapathali Campus from 2012, Eastern Regional Campus and Western Regional Campus from 2013, under Institute of Engineering. Mechanical Engineering Department in Pulchowk Campus has started master programs in Renewable Energy Engineering in 2000, Technology Innovation and Management in 2010, Energy System Planning and Management in 2012 and Mechanical Systems Design and Engineering in 2017. Department has also started offering Ph. D. program since 2005. Similarly, Thapathali Campus has started to offer master program in Mechanical Process Design and Engineering from 2017.

First revision of the curriculum was completed in 1999. Regular curriculum revision is important in academic institution. Second revision of curriculum started in 2009 and completed in 2015. Laboratory facilities, modern equipment suitable for training and research, experienced faculty members are the asset of Department of Mechanical Engineering in Pulchowk Campus.

\section{Methodology}

This study is based on both quantitative and qualitative information. The data is based on documents in the Mechanical Engineering Departments and data of universities abroad were collected from their home pages. Different components of upgradation of Curriculum-1999 to C-2009 is presented. Analytic comparison for improvement in the curriculum were performed Finally, different aspects for developing future curriculums for Bachelors of Mechanical Engineering Degree were suggested, considering curriculums of universities abroad.

\subsection{Description of General Out Lines of Curriculums}

The Institute of Engineering (IOE) is offering this course with the objective of producing high level technical manpower capable of undertaking works in the Mechanical Engineering field. The total duration of the course is four years. Each year consists of two semesters I and II, and having durations 
of ninety working days (fifteen weeks). The course is divided into eight semesters. First year courses include fundamental common subjects. Second and third year generally include specific courses of the related discipline. Final year include professional and application type courses.

Each subject is specified by a unique code consisting of two letters followed by three digit numbers for core courses and five digit numbers for elective courses. Method of teaching is lectured augmented by tutorials and/or practical, whichever is relevant. Tutorials are used to enlarge and develop the topic and concepts, stated in the lectures. Practical classes in the form of laboratory works and design/drawing practices are used to verify the concepts and to develop necessary basic skills. Each course is specified with certain lecture, tutorial and practical contact hour(s) per week. The hours specified as $3 / 2$ in practical means three hours of laboratory classes in each alternate weeks. Use of multimedia and interactive mode (presentations) are encouraged for conducting courses.

Evaluation of courses are performed through continuous assessment. $20 \%$ of the total marks are allocated for internal assessment in theory parts of all courses. Internal assessment mark should include class performance, timely submissions of assignments, class tests, quizzes etc. The evaluation report will be submitted to the examination division. There is the practice to take formal internal assessment examination twice or multiple time and submits average marks among them to the examination division. There are also practices of internal evaluation through home assignments, report writing and viva -voceetc.

Apart from the lecture classes tutorial classes are dedicated to make students familiar with practical problems. Students are assigned analytical problems to find solutions. Teacher assists student in the process. $70 \%$ attendance is mandatory to qualify for the final examination. Final examinations of three hours for theoretical subjects with full mark of eighty and one and half hours for theoretical subjects with full mark of forty are conducted as per curriculum structure of IOE. The distribution of mark for each subject is given at the end of course content provided for instructors in the departmental curriculum. For the final examination purpose, all theoretical subjects are divided into five units. Each unit will carry $20 \%$ of full marks in the final examination. There may be sub questions in each unit but each sub questions can have marks multiple of four only. Student must obtain $40 \%$ in both internal assessment and final examination of each subject to pass in the subject. Only students who have passed the internal assessment of a particular subject are allowed to appear in the final examination of that subject.

\subsection{Features of Curriculums}

In Departmental Curriculum-1999, there are all together fifty-two courses. There are thirteen courses in each year. These courses are offered by Department of Science and Humanities, Civil Department, Electrical Department, Electronics and Computer Department and Mechanical Engineering Department in various semesters. Mechanical courses are mainly offered in lateral semesters. Industrial Attachment course was offered in fourth year first semester of Bachelor Degree in Mechanical Engineering. The consultation hour for the course is one month. Project course are offered in fourth year second semester of Bachelor Degree in Mechanical Engineering. The consultation hour for the course is six contact hours per week. There are two elective courses in first and second semester of fourth year. Student can choose elective course according to their interest. In Curriculum-2009, there are all together fifty courses. There are six courses in each semester except eight courses in seventh semester. 


\section{Data and Analysis}

\subsection{Comparison between Curriculum-1999 and C-2009}

Revision of the curriculums are continuous process. Course curriculums needs to be revised according to developments in field of engineering. Major improvements in existing the curriculums were performed during the time. It can be seen that more electives courses are always in demand. There were only five electives in C-1999. It has added eleven more numbers of elective courses before the revision of C-2009, according to need and development of technology, are given in Table 1.

Table 1: Elective Courses

\begin{tabular}{|c|c|c|}
\hline Electives of $1999 \mathrm{C}$ & Electives added before $2009 \mathrm{C}$ & Electives added before $2009 \mathrm{C}$ \\
\hline $\begin{array}{l}\text { 1. Rural Energy Technology, } \\
\text { (Elective I) } \\
\text { 2. Refrigeration and Air- } \\
\text { conditioning, (Elective I) } \\
\text { 3. Automobile Engineering } \\
\text { (Elective I) } \\
\text { 4. Industrial Engineering and } \\
\text { management (Elective II) } \\
\text { 5. Forecasting Techniques And } \\
\text { Inventory Control (Elective II) }\end{array}$ & $\begin{array}{l}\text { 1. Mini and micro Hydropower } \\
\text { System Design } \\
\text { 2. Operational Research and } \\
\text { Management Science } \\
\text { 3. Micro-Scale Solar } \\
\text { Photoviltaic and Wind } \\
\text { Technology } \\
\text { 4. Solar Thermal Energy } \\
\text { Technology } \\
\text { 5. Vehicular Emissions and } \\
\text { Control }\end{array}$ & $\begin{array}{l}\text { 6. Quality Managment } \\
\text { 7. Finite Element Method } \\
\text { EG766 } \\
\text { 8. An Introduction to } \\
\text { Construction Equiptment } \\
\text { 9. Advanced Machine Desidn } \\
\text { 10. Introduction to Aero-plane } \\
\text { 11. Operations } \\
\text { Research/Management } \\
\text { Science }\end{array}$ \\
\hline
\end{tabular}

The Mechanical Engineering Department and Mechanical Engineering Subject committee are continuously involved in refining curriculum for Bachelor's Degree in Mechanical Engineering. The department and the committee are considering close look on curriculums offered in universities abroad such as Indian Institute of Technology and universities of United States of America. In this regards, Fulbright Scholar Professor Dr. Yogendra Singh Chadda was given this task to compare the Curriculum with international curriculums, in 2008.

Professor Chadda has experience in developing Curriculums in Indian Singapore, Africa and American universities. Professor Chadda has suggested re-sequencing of curriculum and emphasise on inclusion of more computer graphics. It is also suggested to major changes in courses like Engineering Drawings, Material Science, Mechanical Deigns etc.

\subsection{Features of Curriculum-2009}

Revision of syllabus has taken references from universities from India, Singapore, and America. It is decided to bring introductory course related to all Science Department, and common departmental courses to be taught in first two semesters of first year. These courses are made common to students of all faculties in Institute of Engineering.

\subsubsection{Numbers of Courses Offered in Each Semester}

In the Curriculum-1999, subject offered in each semester are not uniform. In the revision of Departmental Curriculum-2009, six subjects are offered in each semester of entire years of the curriculum. Except, eight courses were offered including project work and industrial attachments in seventh semester. More and more times were allocated for non-credit courses like group projects and research works. The depth of course may vary from early years to later years. Some courses do not 
seek for practical courses. The Subjects which needs practical classes are indicated in the respective curriculum. Directive or self-learning, researches, visits and presentations are encouraged.

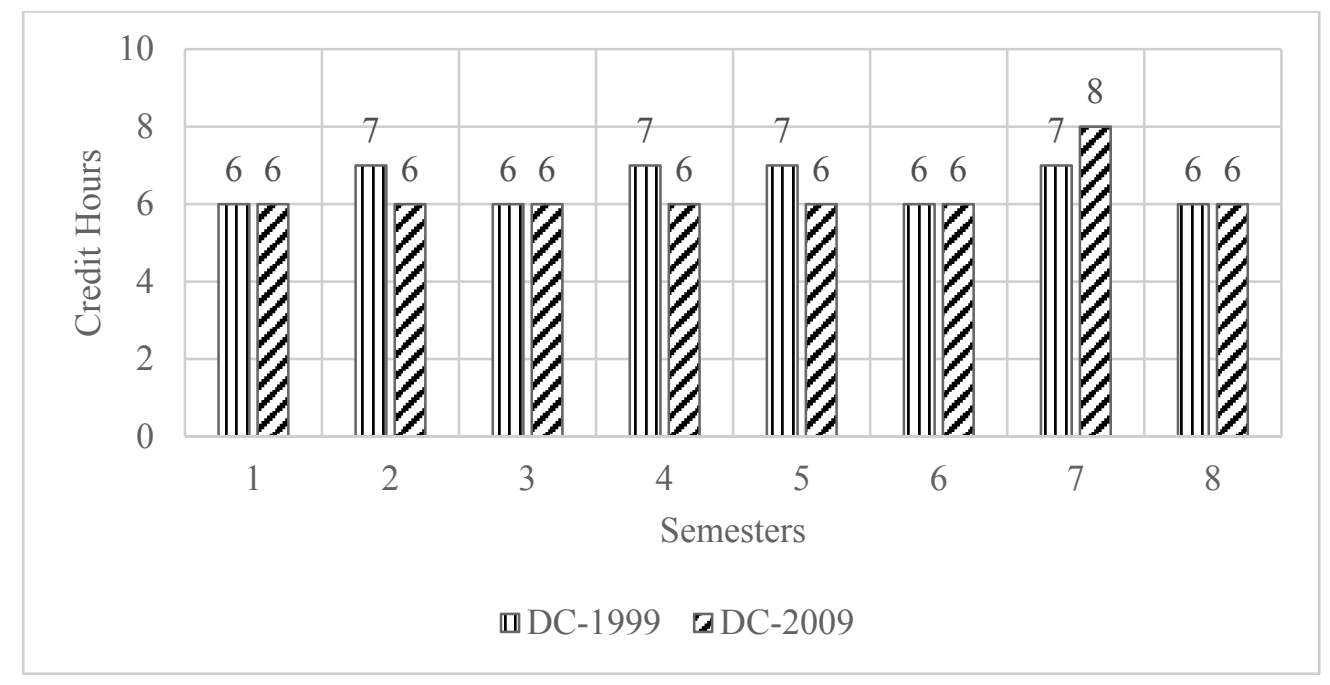

Fig 1: Numbers of courses offered in each semesters in 1999 and 2009 Departmental Curriculums

\subsubsection{Re-sequencing the Subjects}

In the Curriculum-1999, subject offered were re-sequenced. Some subjects like CAD, which was offered in final year, were brought in first year. In the revision DC-2009, subjects like mechanics, design, thermodynamics, heat transfer, fluid mechanics were sequenced according to the knowledge required for students in the frame work.

\subsubsection{Offering of Electives}

Mechanical Engineering Department is offering of latest and useful electives even before the Revision of C-2009. Further elective numbers have increased in the revision. The objective of this is to give in-depth knowledge of professional courses. These electives are offered in small number of student groups (normal size is twelve to eighteen). Further these electives are grouped so that students are facilitated to expertise in a particular specialization. Three elective courses are made mandatory for each student in seventh and eight semesters of the academic duration. Electives courses are grouped as follows:

Table 2 Electives groups in Curriculum-2009

\begin{tabular}{|c|l|c|l|}
\hline SN. & \multicolumn{1}{|c|}{ Electives groups } & SN. & \multicolumn{1}{|c|}{ Electives groups } \\
\hline 1 & Automobile & 2 & Thermodynamics \\
\hline 3 & Bio Energy & 4 & Management \\
\hline 5 & Energy (Hydropower) & 6 & Design \\
\hline
\end{tabular}

\subsubsection{Industrial Attachment Course}

Department of Mechanical engineering offers attachment course as Industrial Attachment. in fourth year second semester of the bachelor degree. Course objectives of Industrial Attachment is to explore academic knowledge in the respective industries and to become familiarised with the contemporary industrial condition in Nepal. 
Industrial Attachment will be conducted for one-month duration i.e. September and October, semester break in the calendar. Students prepare attachment group members, selection of industries, literature study of the industries, beforehand. Brief introduction will be conducted by the departmental Industrial Attachment Committee. It will provide different steep to be performed by the students during the attachment. Students are advised not to perform:

i. Violet Rules and laws of the respective industries.

ii. Perform activities that will directly or indirectly harm industrial environment.

Each attachment group has to be present in the corresponding industries for thirty working days. The person responsible in the industries has to evaluate the performance of the student and he has to send the evaluation form along with student's attendance to the department. After completing the Industrial Attachment, each group has to submit reports in the prescribed format to the department. Schedule for submission of report and presentation will be announced by the department. Each group has to give presentation for half an hour to the Industrial Attachment Committee. Quires and suggestion by the committee will be done. Each group will finally resubmit the report incorporating all the suggestions by the committee. The evaluation will be fifty to fifty percentages from industrial side and Industrial Attachment Committee of the department. Represent from respective industries may be invited during the presentation and final copy of the report will be provided to the respective industries.

\subsubsection{Project Course Offered by the Department}

Department of Mechanical engineering offers course on Project in fourth year first and second semester of Bachelor Degree in Mechanical Engineering. The consultation hour for the course is three and six contact hours per week for seventh and eight semesters. From third year of academic session students start selecting project titles and literature studies.

Objective of Project course is to plan and complete an individual mechanical engineering design project under the supervision of a faculty member in the Department of Mechanical Engineering. Finally, prepare written report and give oral an examination.

The project course will involve working on a design project under the supervision of a faculty member in the Department of Mechanical Engineering. The subject of the project should be as relevant as possible to the local industrial environment and may be selected in consultation with an industrial firm or government departments.

- A detailed project proposal is to be submitted to the head of department within two weeks of the start of the seventh semester. The HOD and supervisor will decide whether the project is accepted or not. An oral presentation (10 minutes plus 10 minutes for questioners) will take place at a convenient time of supervisor and evaluation committee of the department. The written proposal and oral reports will be accounted for final evaluation.

- A written mid-term progress report is to be submitted 2-3 weeks before the end of the semester (Part I of the fourth year). An oral presentation (15 minutes plus 15 minutes for questioners) will take place at a convenient time of supervisor and evaluation committee. The proposal and midterm (written and oral reports) presentation will carry fifty marks.

- Final written report (in the provided format by department) will be submitted before the end of $12^{\text {th }}$ week of the eighth semester (4" year, Part II). This report will be evaluated by the supervisor, members of examination committee and external examiner. This will carry fifty marks. 
An oral examination of the final report will be conducted during the 15 week of the eighth semester ( $4^{\text {th }}$ year, Part II) at a time convenient to the examination committee, supervisor and the student. The final oral examination will carry fifty marks.

\subsubsection{Contact Hours for Courses}

Different subject seeks for various combinations of direct lectures, tutorials, practical classes. Over all contact hours is nearly same, are 252.5 and 251 in both 1999 and 2009 Curriculum, respectively. There is slightly decrease in direct lecture and tutorial contact hours in C-1999 with respect to C2009. Emphasis were given in practical and research works that increases from 72.5 to 77 contact hours during entire four year courses in C-2009, as shown in Figure 2.

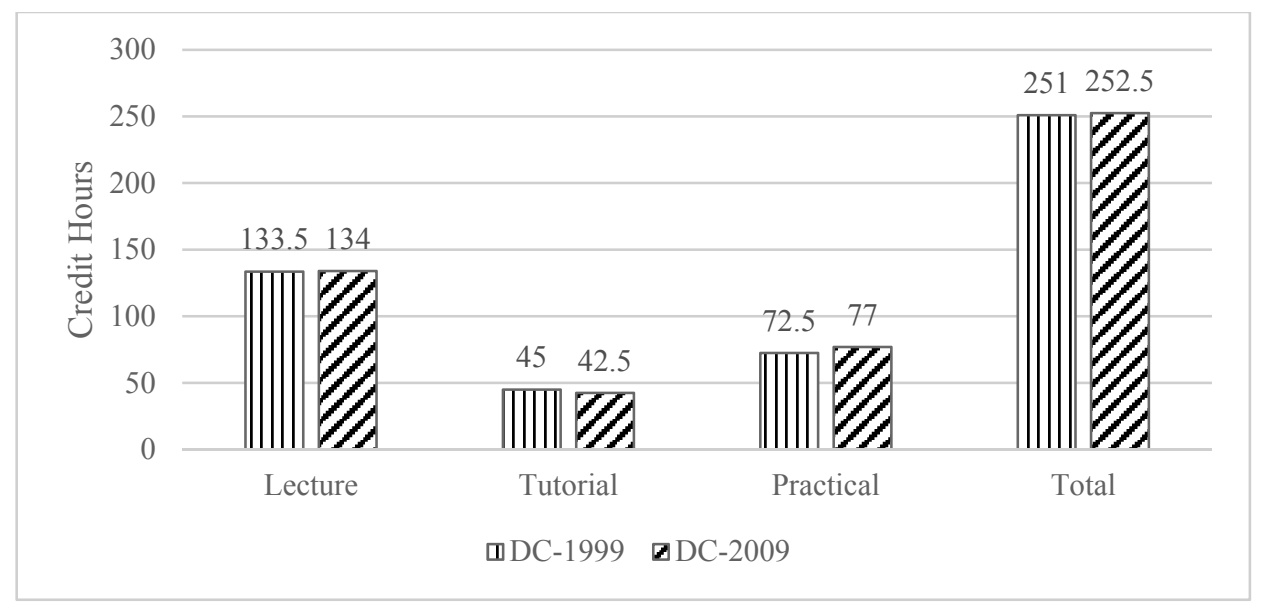

Fig. 2: Contact Hours for Lecture, Tutorial, Practical and Total Courses

\subsection{Comparing of Curriculum with Contemporize Universities}

Comparative study was performed among Mechanical Engineering Curriculums of Sirindhorn International Institute of Technology Thammas at University Thailand (SIILT), Indian Institute of Technology Bombay India(IIT Bombay), Indian Institute of Technology Delhi India (IIT Delhi), Institute of Engineering, Tribhuvan University Nepal (IOE) andBangladesh University of Engineering and Technology Bangladesh (BUET).Direct lecture contact hours are better in the Departmental Curriculum of IOE, which is more than 120 contact hours necessary for of US credit system. The calculation for IIT Bombay seems less but they use two hours contact hours for one credit of lecture hours.

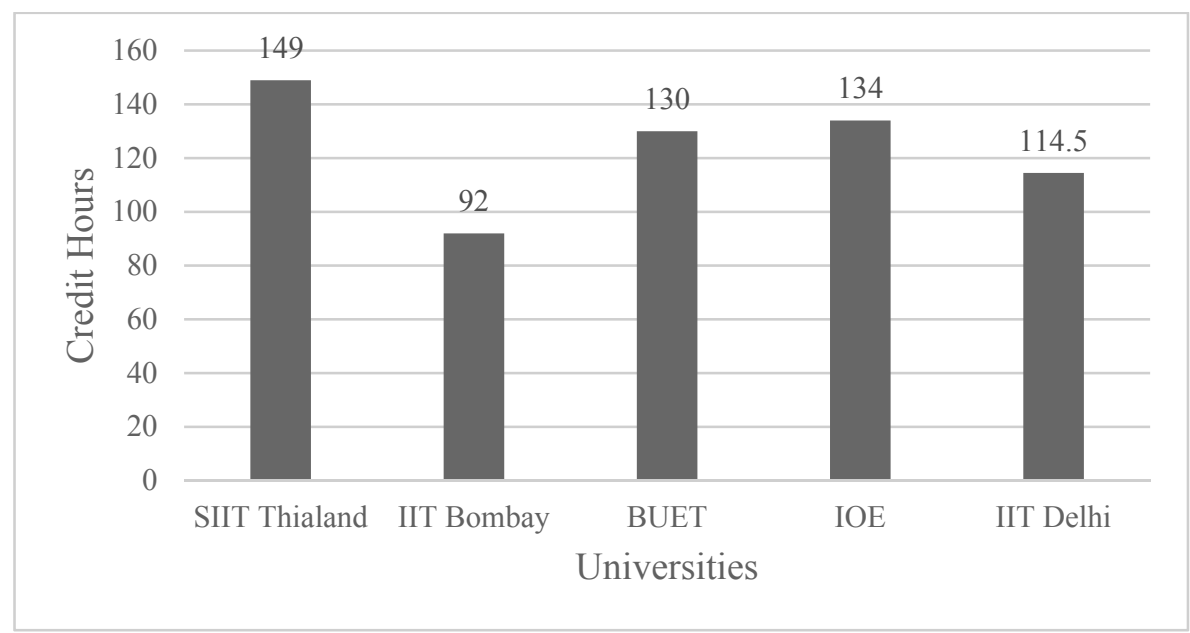

Fig. 3: Credit Hours in Different Universities 
Different courses are grouped as Basic Science group, Other Engineering group, Mechanics and Design group, Production and Management group, Thermo-Fluid group and Elective Project group. Credit hours of these groups in these universities are compared and average credit hours are also plotted, as shown in Figure 4.

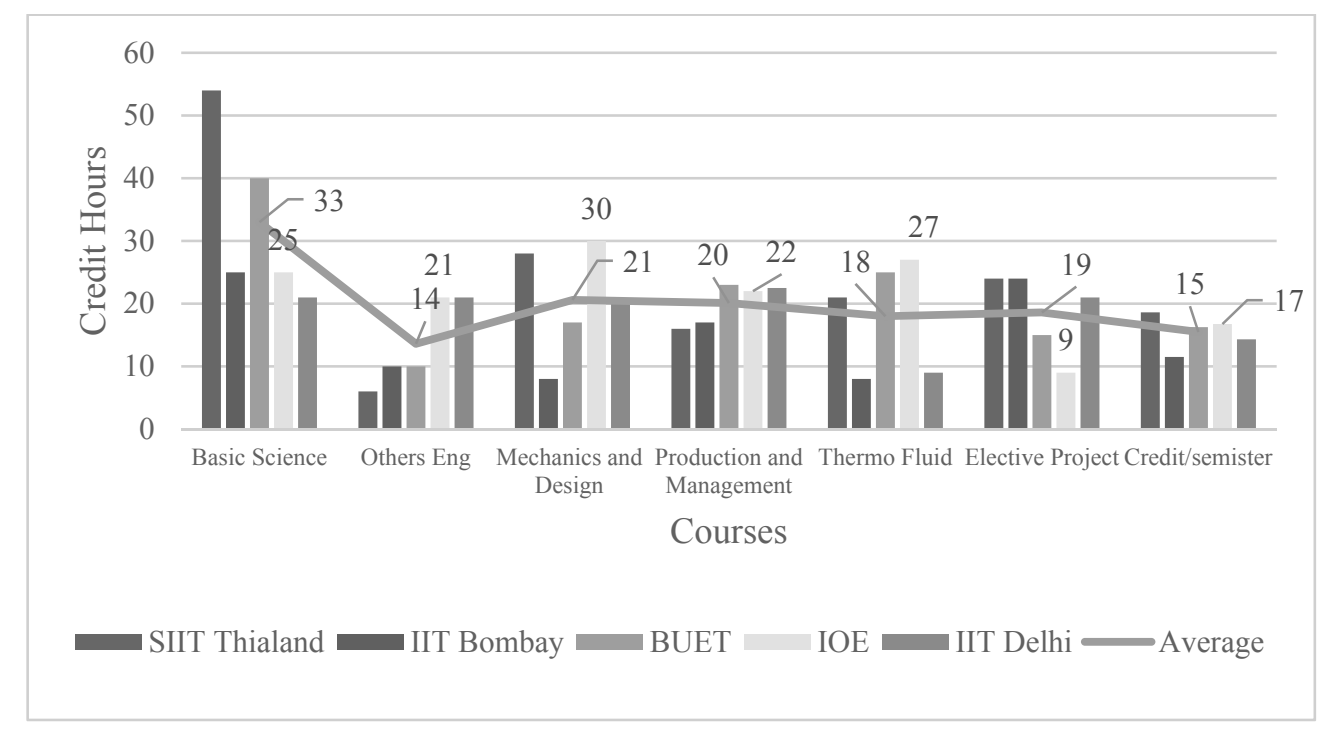

Fig. 4: Credit Hours for Different Groups of Coerces in Different Universities

It can be observed from the Figure 4 that, credit hours in most of the subject groups in the IOECurriculum is satisfactory and around the average values. There is some lagging in Basic Science group but it is close to average. This can be balanced by offering courses in other groups. The most lagging part in the IOE Curriculum is in the credit hours of elective subject groups. The average value of credit hours for the elective subject groups is nineteen credit hours, whereas in the IOECurriculum offers only nine credit hours of courses. This urge to increase elective course credit hours in the IOE Curriculum.

\subsection{Accreditation of Courses}

In both in IOE C-1999 and C-2009, total hours for direct lectures are more than 120 credit hours, needed for accreditation in universities of United States of America.A "CREDIT HOUR" is the unit of measuring educational CREDIT, usually based on the number of direct lecture hours per week throughout a term. In American universities, a semester unit of credit as equal to a minimum of three hours of work per week for a semester. Thus, a unit of credit equates to three hours of student work per week ( 1 hour lecture plus 2 hours of homework or 3 hours of lab) for 16 weeks. In certain circumstances, it is possible to have more hours, but not less than five working days per week. [6].While the length of a semester may vary, is based upon a minimum length of 16 weeks. But there are variation in the length from 13 to 16 in American Universities and Universities following Bologna System in Europe [6]. The duration taken in IOE Curriculum is considered as 15 weeks for a semester, six working days per week.

A typical UK bachelor's degree with 360 UK credits is equivalent to 180 ECTS (European Credit Transfer and Accumulation System) credits. Thus, one ECTS credit is equal to two UK credits. ECTS credits for postsecondary education also take into consideration both instruction time and selfpreparation time, along with other academic activities (for example, examinations). For ECTS, a year of study comprises sixty credits, including auditorium hours and self-preparation[5]. The total credit 
earned in IOE Curriculum and USA will be two times of 120 that will be 240 ECTS credits in Bologna system.

As explained before, in Bologna system and US credit system, seeks for two times of direct lecture urges to have related assignments or tutorial work or report or project or practical work. But in the IOE Curriculum related assignments or tutorial work or report or project or practical work is less than 120 contact hours during four years of full duration. It will be better to have the supporting contact hours as two times of minimum direct lecture contact hours. This is most lagging part in the IOE Departmental Curriculum. The IOE Departmental Curriculum needs to increase the supporting contact hours, in their Departmental Curriculum and facilitates for conducting the same, properly.

\subsection{Laboratories and Research Works}

Experiments and research works are important in engineering education. Credit hours for practical courses including research and project have increased to 77 credits hours in C-2009 from 73 credit hours in C-1999. There are all together thirteen workshops and laboratories in the Mechanical Engineering Department of Pulchowk Campus. There are lesser lab facilities in other campuses, Thapathali Campus, Eastern Campus and Western Campus. List of workshops and laboratories in Mechanical Engineering Department of Pulchowk Campus is as given Table 3.

Table 3: List of Laboratories

\begin{tabular}{|c|l|c|l|}
\hline SN. & \multicolumn{1}{|c|}{ Workshops and Laboratories } & SN. & \multicolumn{1}{|c|}{ Workshops and Laboratories } \\
\hline 1 & Fluid Mechanics and Fluid Machine & 2 & Material Science \\
\hline 3 & Thermodynamics and Heat Transfer & 4 & $\begin{array}{l}\text { Strength of Material and Mechanics } \\
\text { of Solid }\end{array}$ \\
\hline 5 & $\begin{array}{l}\text { Workshop (Basic tool, Machine and Sheet } \\
\text { Metal) }\end{array}$ & 6 & Energy Resources \\
\hline 7 & Instrumentation, Control and Measurements & 8 & Environment and Pollution Control \\
\hline 9 & Computer & 10 & Graphics \\
\hline 11 & Mechanism and Machine Dynamics & 12 & Turbo Machine \\
\hline 13 & Internal Combustion Engines & & \\
\hline
\end{tabular}

The departmental equipment in Workshop and laboratories seems little bit bench type and urge for contemporary equipment and research-type according to latest technologies. It is necessary to develop welding sets, 3D printers, visualization set etc. Concept of virtual laboratories needs to be developed, further simulating type of research could be included.

\section{Conclusion and Discussion:}

Curriculum revision is one of the important part of the Bachelor Degree in Mechanical Engineering. Regular work to revise curriculums is necessary in academic institutions. First revision of the curriculum was completed in 1999. Second revision of curriculum performed in 2009.

Curriculum revision-2009 has sequenced the subjects offered according to the knowledge required for students. Industrial attachment courses and project courses offered by the department were made more 
organised. The average value of credit hours for the elective subject groups is nineteen credit hours in contemporary universities, whereas in the IOE Curriculum offers only nine credit hours of courses. This urge to increase elective course credit hours in the IOE Curriculum.

In Bologna system and American universities credit system, for a unit credit hour direct lecture course urges to have twice the related assignments or tutorial work or report or project or practical work. The IOE Curriculum needs to increase this supporting contact hour, in their Curriculum and facilitates for conducting the same, properly.

Some equipment in workshop and laboratories are demo type and need for better and research-type equipment, according to the latest technologies.

\section{Reference}

1. Courses of Study 2017-2018, "Undergraduate program", Bachelor of Technology, Indian Institute of Technology Delhi, India, http://www.iitd.ac.in

2. “Curriculum Bachelor's Degree in Mechanical Engineering 1999”, Pulchowk Campus, IOE, TU

3. “Curriculum Bachelor's Degree in Mechanical Engineering 2009”, Central Campus Pulchowk, IOE, TU

4. "Department of Mechanical Engineering”, Pulchowk Campus Pulchowk, http://mech.pcampus.edu.np/

5. "ECTS Users' Guide", Luxembourg: Office for Official Publications of the European Communities, 2009, ISBN: 978-92-79-09728-7, doi: 10.2766/88064

6. Igor F. Tsigelny, "Educational Credits in the USA and Credit Transfer from the UK and European Union", Analytical Reports in International Education METHODS, Vol. 4. No. 1, November 2011, pp. 87-93

7. Institute of Engineering, Tribhuvan University, Nepal, http://ioe.edu.np/

8. "Rules, Regulations and Syllabuses for the degree of B. Sc. Engineering (Mechanical)”, June 2007, Department of Mechanical Engineering, Bangladesh University of Engineering and Technology Dhaka-1000, Bangladesh

9. Pahari Bharat Raj "The Reform in Evaluation System as a Tool of Quality Improvement in Institute of Engineering”,Journal of the Institute of Engineering, Vol. 10, No. 1, pp. 1-13

10. "Undergraduate Catalog, Academic Year 2016", Sirindhorn International Institute of Technology Thammasat University Thailand

11. "Undergraduate Curriculum", Bachelor Structure- 2013 Batch onward, Department of Mechanical Engineering, Indian Institute of Technology Bombay, India,http:// www.me.iitb.ac.in/academics/ug/ugdetailedcurriculum/ 